\title{
Detailed Gas Dynamic Study of Performances for Two TYPES TURBOFAN CONFIGURATIONS
}

\author{
Catana Razvan-Marius, Cican Grigore \\ National Research and Development Institute for Gas Turbines COMOTI, 220 D Iuliu Maniu Bd., 6, cod 061126, \\ OP76, CP174, Bucharest, Romania
}

\begin{abstract}
The paper presents a mathematical method to compute the performance of two different types of turbofan engines, one type is the turbofan with axial air flows, classical turbofan, and the second type is a turbofan with radial-axial air flows, a new turbofan configuration. To compare the engines specific parameters of the classical engine will be confronted to the new engine configuration. The engines are compared only in gas-dynamic calculus and not in technical constructive solution. By this gas-dynamic study is intended to establish the difference between the engines in thrust, fuel consumption and acoustic power.
\end{abstract}

Keywords: engine configuration; axial flow turbofan; radial-axial flow turbofan; engine parameters
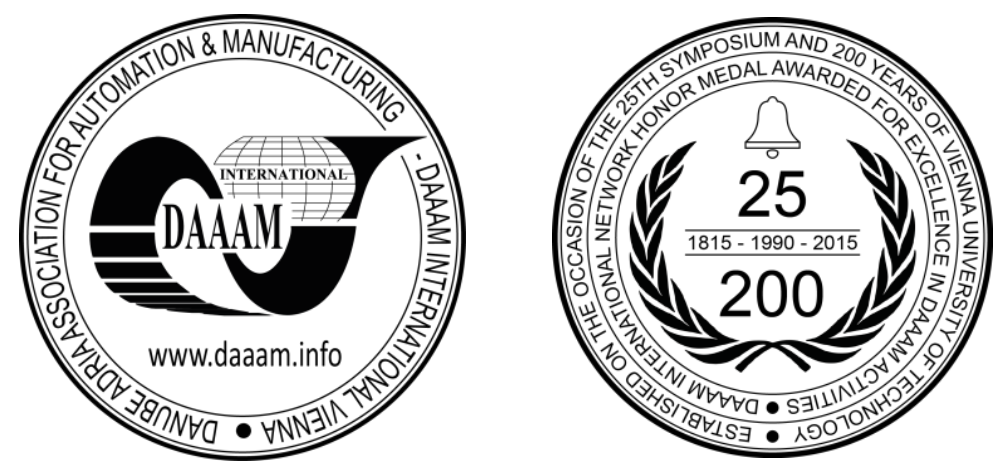

This Publication has to be referred as: Catana, R[azvan] \& Cican, G[rigore] (2016). Detailed Gas Dynamic Study of Performances for Two Types Turbofan Configurations, Proceedings of the 26th DAAAM International Symposium, pp.0166-0172, B. Katalinic (Ed.), Published by DAAAM International, ISBN 978-3-902734-07-5, ISSN 1726-9679, Vienna, Austria DOI:10.2507/26th.daaam.proceedings.023 


\section{Introduction}

The main issues faced by the civil aviation, globally, are the carbon dioxide emissions with negative impact over the environment and, locally, the noise pollution with negative impact over the residential areas near the airports and the personnel working in the airports.

Next generation aircraft entering service in 2020 have the potential to achieve range increases of up to $50 \%$ or reductions in fuel burn of up to $30 \%$ relative to a year 2000 airplane, this will be possible by introducing a new generation of propulsion systems for different types of turboengines with the new concepts of turboengines[1], turboshaft[2] models and new concepts of airplane[3].

A series of measurements and objectives that need to fulfill the civil aviation for protecting the environment[4]. In this scope there are different concepts and detailed phases for this purpose [5].

The main method to control the carbon dioxide emission is to reduce the cosumption of turbofan fuel.

The thrust of turbofan engine is $80 \%$ realizated by the fan that divides the engine airflow into the primary air flow and secondary air flow defined by the bypass ratio. Starting on clasical turbofan[6] which is a axial flow, dualrotor engine, with the primary air flow and the secondary air flow that enters in the engine in the same air inlet, coming from the same rotor axial fan and on the same axial direction. The thrust of the engine is the sum of the primary flow thrust and secondary flow thrust. The operating principle of the clasical turbofan engine is presented in Fig.1. The new turbofan[7] is a different gas-dynamic configuration and a technical constructive solution of the inlet of air flows, is a dual-rotor engines with the inlet of primary flow separately from the inlet secondary air flow, comes from separated rotors, the primary air flow comes from LPC rotor and the secondary air flow comes from the FAN rotor. The thrust of engine is the same sum of the primary flow thrust and secondary flow thrust. The operating principle of the new type of turbofan engine is presented in Fig. 2.

This paper will present a new configuration of a turboengine that tries to reduce the fuel consumption, to increase force and to reduce the noise pollution.

\section{Axial flow and radial-axial flow turbofan configurations}

The axial flow turbofan configuration of the primary air flow [8] is defined by the $\mathrm{M}_{\mathrm{a} . \mathrm{I}}$ air flow and the secondary flow is defined by $\mathrm{M}_{\mathrm{a} . \mathrm{II}}$ air flow. The combustion gases are defined by $\mathrm{M}_{\mathrm{g}}$ gas flow. The thrust of primary flow is caracterizated by $M_{g}$ gas flow and secondary flow by the $M_{\text {a.II }}$. The bypass ratio $K_{F . E 1}$ for classical engine is defined as ratio between $M_{\text {a.II.E.1 }}$ and $M_{\text {a.I.E.1. }}$

Radial-axial flows turbofan engine in configuration of the primary flow defined by $\mathrm{M}_{\mathrm{a} . \mathrm{I}}$ air flow and the secondary flow defined by $\mathrm{M}_{\mathrm{a} . \mathrm{F}}$ air flow where the gas flow $\mathrm{M}_{\mathrm{g}}$ from the primary flow is evacuated into the secondary flow of the turbofan. The bypass ratio $K_{F . E 2}$ for new turbofan engine is defined as ratio between $\mathbf{M}_{\text {a.F.E2 }}$ and $\mathbf{M}_{\text {a.I.E2. }}$.

The axial flow and radial-axial turbofans have the same gas-dynamic configuration but different constructive solutions. Axial flow engine used for the core engine, the air from the fan and radial-axial flow engine used for the core engine, the air not from the fan and from the outside of the engine.

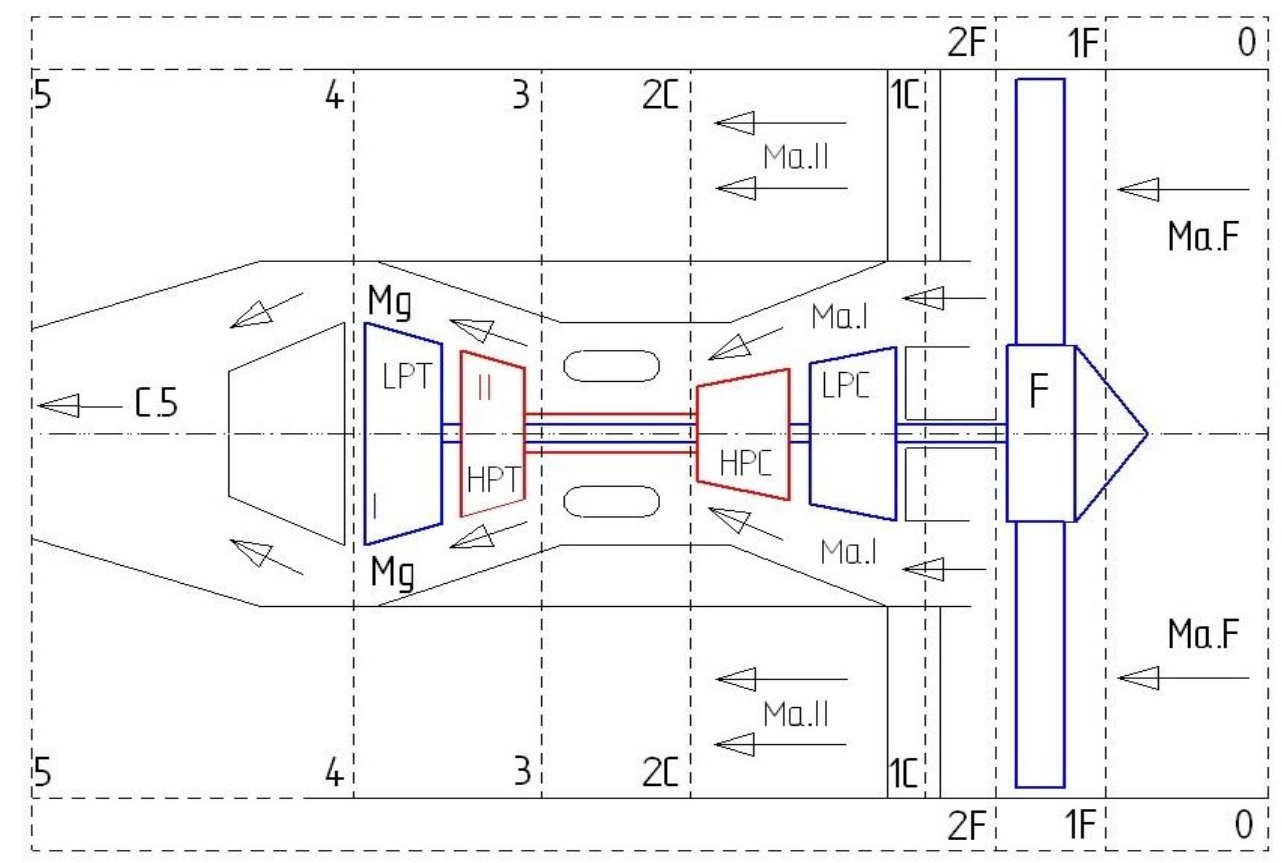

Fig. 1. The axial flow turbofan engine scheme 


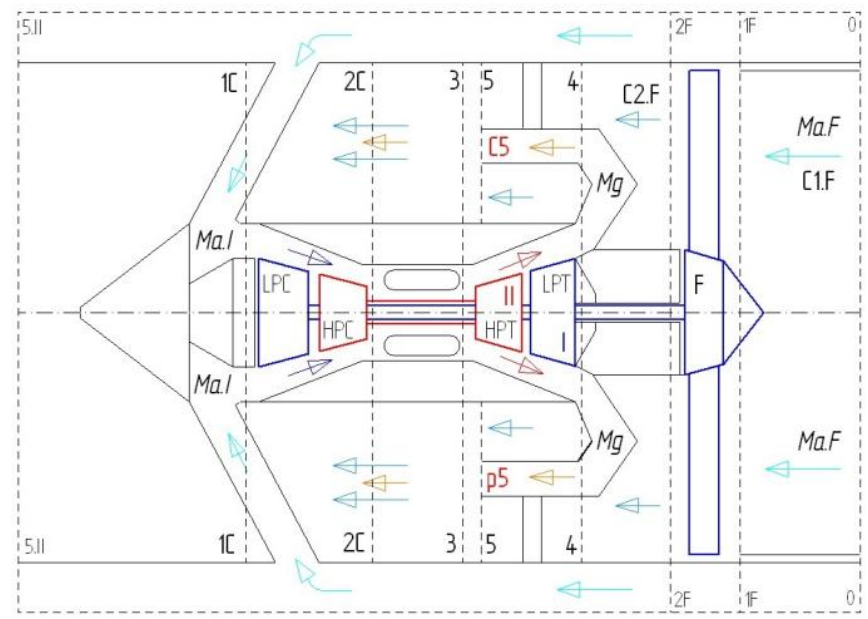

Fig. 2. Radial-axial flow turbofan engine scheme

The radial-axial flow turbofan engine is characterized by inlet of the primary flow because has a different position, a radial direction of flow and different geometry than the inlet for the secondary flow, so that the air flow $\mathrm{M}_{a . I}$ from the primary flow represents the air flow aspirated by the LPC and the air flow $\mathrm{M}_{\mathrm{a} . \mathrm{F}}$ from the secondary flow is the air flow aspirated by the FAN. The LPC and the FAN receive power from the LPT. The primary flow admission is performed from the outside of the engine on a radial direction by inlet profiled mounts. The air flow $\mathrm{M}_{\mathrm{a} . \mathrm{I}}$ is aspirated by LPC, which receives power from the LPT. The burning of the mixture of air and fuel is performed in the combustion chamber and result gas flow $\mathrm{M}_{\mathrm{g}}$. The gas flow is directed by profiled exhaust mounts in the secondary air flow. The air flow $M_{a . F}$ it is aspirated at environment pressure and temperature $p_{0}, T_{0}, T_{0}$ with the entering velocity $C_{1 . V}$ and it is accelerated by the fan rotor up to the $\mathrm{C}_{2 . \mathrm{v}}$ achieved the thrust of secondary air flow.

\section{Gas-dynamic configuration of the axial flow and radial-axial flow turbofan}

Because the axial flow engine(E1) has the same gas-dynamic configuration with the radial-axial flow engine(E2), the equations of total energy conservation of rotors for turbofan engines are defined in the next set of equations[9] represented by the transfer of power between rotors. The power turbine is transferred to the low pressure compressor and the fan, from LP rotor and to the high pressupre compressor from HP rotor.

$$
\begin{aligned}
& \mathrm{P}_{\text {T.II.E1,2 }}=\mathrm{P}_{\text {C.II.E1,2 }} \\
& \mathrm{P}_{\text {T.I.E1,2 }}=\mathrm{P}_{\text {C.I.E1,2 }}+\mathrm{P}_{\text {F.I.E1,2 }} \\
& \mathrm{P}_{\text {T.E1,2 }}=\mathrm{P}_{\text {T.II.E1,2 }}+\mathrm{P}_{\text {T.I.E1,2 }}=\mathrm{P}_{\text {C.II.E1,2 }}+\mathrm{P}_{\text {C.I.E1,2 }}+\mathrm{P}_{\mathrm{F} . E 1,2}
\end{aligned}
$$

The total specific actual work [7] of turbine has the same configuration with a small modification of fan actual work coefficient because of the bypass ratio is different defined.

$$
\begin{aligned}
& 1_{\text {T.t.E1 }}=1_{\text {T.II.t }}+1_{\text {T.I.t }}=1_{\text {C.II.t }}+1_{\text {C.I.t }}+\left(1+\mathrm{K}_{\text {F.E1 }}\right) \cdot 1_{\text {F.t }} \\
& 1_{\text {T.t.E2 }}=1_{\text {T.II.t }}+1_{\text {T.I.t. }}=1_{\text {C.II.t }}+1_{\text {C.I.t. }}+\mathrm{K}_{\text {F.E2 }} \cdot 1_{\text {F.t }}
\end{aligned}
$$

To compare the performance of the engines it is established that the engines has three common parameters. These parameters are power of turbine, engine overall pressure ratio, inlet turbine temperature and are defined by the next set of equations (6).

$$
\left\{\begin{array}{l}
\mathrm{P}_{\mathrm{T} . \mathrm{E} 1}=\mathrm{P}_{\mathrm{T} . \mathrm{E} 2} \\
\pi_{\mathrm{E} 1 . \mathrm{t}}=\pi_{\mathrm{E} 2 . \mathrm{t}} \\
\mathrm{IIT}_{\mathrm{t} . \mathrm{E} 1}=\mathrm{ITT}_{\mathrm{t} . \mathrm{E} 2}
\end{array}\right.
$$


The overall pressure ratio of the engines are equal in value but different in configuration.

$\left\{\begin{array}{l}\pi_{\text {E1.t }}=\pi_{\text {F.t.E1 }} \cdot \pi_{\text {C.I.t.E1 }} \cdot \pi_{\text {C.II.t.E1 }} \\ \pi_{\text {E2.t }}=\pi_{\text {C.I.t.E2 }} \cdot \pi_{\text {C.II.t.E2 }}\end{array}\right.$

Starting from an axial flow engine turbofan with known engine parameters, it is calculated the power of HPT and LPT turbines and in the end of calculating the engine performance, thrust and specific fuel consumption.

The known parameters for the axial turbofan one are: $\pi_{\mathrm{F} . t . \mathrm{E} 1}=1.5, \eta_{\mathrm{F} . \mathrm{t} . \mathrm{E} 1}=0.87, \pi_{\mathrm{C} . \mathrm{I} . \mathrm{t} . \mathrm{l} 1}=2.5$, $\eta_{\text {C.I.t.E1 }}=0.87, \pi_{\mathrm{C} . I I . t . E 1}=8$, $\eta_{\text {C.II.t.E1 }}=0.83$, ITT.E1 $=1475\left[{ }^{\circ} \mathrm{C}\right], \eta_{\text {T.II...E1 }}=0.89, \eta_{\text {T.I.t.E1 }}=0.87$

For different values of the fan overall pressure and for the same turbine inlet temperature it is calculated the bypass ratio of radial-axial turbofan with the next equation.

$\mathrm{K}_{\text {F.E2 }}=\frac{1_{\text {T.I.t. }}-\left(1_{\text {C.I.I.t }}+1_{\text {C.I.t. }}\right)}{1_{\text {F.t. }}}$

Having the bypass ratio it is necessary to compute the primary air flow and secondary air flow. From equations (9) it is calculated the overall pressure ratio of the fan for the second engine and the overall pressure ratio of LPC and HPC depending on inlet enthalpy of fan and compressor.

$$
\begin{aligned}
& 1_{\text {F.t.E1,2 }}=\frac{h_{1 . F . t . E 1,2}}{\eta_{\text {F.t.E1,2 }}} \cdot\left(\pi_{\mathrm{F} . t . E 1,2}^{\frac{\mathrm{k}-1}{\mathrm{k}}}-1\right) \\
& 1_{\text {C.I,II.t.E1,2 }}=\frac{\mathrm{h}_{1 . \text { C.I,II.t.E1,2 }}}{\eta_{\text {C.I,II.t.E1,2 }}} \cdot\left(\pi_{\text {C.I,II.t.E1,2 }}^{\frac{\mathrm{k}-1}{\mathrm{k}}}-1\right)
\end{aligned}
$$

Using the parameters that are just calculated it is necessary to calculate the velocity [4] for the gases flow and secondary air flow derived from the fan. For both types of engines the gases flow velocity and secondary air flow velocity are calculated in the same form represented by equations (11) and (12)

$$
\begin{aligned}
& \mathrm{C}_{5 . I . E 1,2}=\varphi_{\mathrm{ar}} \cdot \sqrt{2 \cdot\left(\mathrm{h}_{4 . t . E 1,2}-\mathrm{h}_{\text {5.I.E1,2}}\right)} \\
& \mathrm{C}_{\text {5.II.E1,2 }}=\varphi_{\mathrm{ar}} \cdot \sqrt{2 \cdot\left(\mathrm{h}_{\text {2.F.t.E1 }}-\mathrm{h}_{\text {5.II.E1 }, 2}\right)}
\end{aligned}
$$

Having the velocities and air flows the engine performance of both type of engines, thrust and specific fuel consumption can be calculated with the next set of equations (13)

$$
\left\{\begin{array}{l}
\mathrm{F}_{\mathrm{I}, \mathrm{E} 1,2}=\mathrm{C}_{5 . \mathrm{I} . \mathrm{E} 1,2} \cdot \mathrm{M}_{\mathrm{g} . \mathrm{E} 1,2} \\
\mathrm{~F}_{\mathrm{II}, \mathrm{E} 1}=\mathrm{C}_{5 . \mathrm{II} . \mathrm{E} 1} \cdot \mathrm{M}_{\text {a.II.E1 }} \\
\mathrm{F}_{\mathrm{II}, \mathrm{E} 2}=\mathrm{C}_{5 . \mathrm{II} . \mathrm{E} 2} \cdot \mathrm{M}_{\text {a.F.E2 }} \\
\mathrm{F}_{\text {P.E1,2}}=\mathrm{F}_{\text {P.I.E1,2}}+\mathrm{F}_{\text {P.II.E1 }, 2} \\
\mathrm{C}_{\mathrm{spE} 1,2}=3600 \cdot \frac{\mathrm{M}_{\text {C.E1 }, 2}}{\mathrm{~F}_{\text {P.E1 }, 2}}
\end{array}\right.
$$

To evaluate the engine's noise level and to establish which engine is more silent, it is determined the acoustic power and noise level calculated by the equation [10]. 
$\mathrm{W}_{\mathrm{I}, \mathrm{II} \cdot \mathrm{El}, 2}=\frac{\rho_{5 . \mathrm{I}, \mathrm{II} \cdot \mathrm{El}, 2}}{\rho_{0}} \cdot\left(\frac{\mathrm{C}_{5 . \mathrm{I}, \mathrm{II} \cdot \mathrm{El}, 2}}{\mathrm{a}_{0}}\right)^{6} \cdot \mathrm{M}_{\mathrm{a}, \mathrm{g} . \mathrm{E} \mathrm{I}, \mathrm{l}} \cdot\left(\mathrm{C}_{5 . \mathrm{I}, \mathrm{IIIEI}, 2}\right)^{2}$

$\mathrm{L}_{\mathrm{W} . \mathrm{I}, \mathrm{II} . \mathrm{E} 1,2}=10 \log \left(\frac{\mathrm{W}_{\mathrm{I}, \mathrm{II} . \mathrm{E} 1,2}}{10^{-12}}\right)$

Where $\rho_{0}$ is the air density, $\rho_{5 . \mathrm{I}, \mathrm{IIIEI}, 2}$ is the gas density, $\mathrm{a}_{0}$ is the speed of sound, $\mathrm{C}_{5 . \mathrm{IIIIEI}, 2}$ is the exhaust velocity and $\mathrm{M}_{\mathrm{a}, \mathrm{g} . \mathrm{E} 1,2}$ is the flow.

To present into a comparative form the parameters of the radial-axial turbofan it is defined the next set of parameters

(16) for fan power, primary air flow, LPC and HPT power to evaluate in values the difference between the engines.

$$
\left\{\begin{array}{l}
\mathrm{M}_{\text {a.I.\% }}=\left|\left(1-\frac{\mathrm{M}_{\text {a.I.E2 }}}{\mathrm{M}_{\text {a.I.E1 }}}\right) \cdot 100\right| \\
\mathrm{P}_{\mathrm{F} . \%}=\left|\left(1-\frac{\mathrm{P}_{\mathrm{F} . \mathrm{E} 2}}{\mathrm{P}_{\mathrm{F} . \mathrm{E} 1}}\right) \cdot 100\right| \\
\mathrm{P}_{\mathrm{C} . \mathrm{I} \%}=\left|\left(1-\frac{\mathrm{P}_{\text {C.I.E2 }}}{\mathrm{P}_{\text {C.I.E1 }}}\right) \cdot 100\right| \\
\mathrm{P}_{\text {C.II.\% }}=\left|\left(1-\frac{\mathrm{P}_{\text {C.II.E2 }}}{\mathrm{P}_{\text {C.II.E1 }}}\right) \cdot 100\right|
\end{array}\right.
$$

To compare the result of the engines performance it is defined the performance parameters in percent of new engine turbofan for thrust, fuel consumption and noise level defined by the next equations.

$\mathrm{F}_{\mathrm{P} . \%}=\left(\frac{\mathrm{F}_{\mathrm{P} . \mathrm{E} 2}}{\mathrm{~F}_{\mathrm{P} . \mathrm{E} 1}}-1\right) \cdot 100, \mathrm{C}_{\mathrm{SP} . \%}=\left(1-\frac{\mathrm{C}_{\mathrm{SP} . \mathrm{E} 2}}{\mathrm{C}_{\mathrm{SP} . \mathrm{E} 1}}\right) \cdot 100, \mathrm{~L}_{\mathrm{W} . \%}=\left(1-\frac{\mathrm{L}_{\mathrm{W} . \mathrm{E} 2}}{\mathrm{~L}_{\mathrm{W} . \mathrm{E} 1}}\right) \cdot 100$

\section{Results}

Through the theoretical method to compare two different configurations of turbofan engine it was performed a computing program to determine the engine performance to evaluate the thrust $\mathrm{F}_{\mathrm{p} \%}$ and the specific fuel consumption $\mathrm{C}_{\mathrm{SP} \%}$. The results are diagrams with variation curves of thrust and fuel consumption, function of the bypass ratio $\mathrm{K}_{\mathrm{F} . \mathrm{E}}$ and overall pressure ratio $\pi_{\mathrm{F} . \mathrm{E} . \mathrm{E}}$ of the fan at constant inlet turbine temperature $\mathrm{ITT}_{\mathrm{R}}$

The first set of diagrams from fig. 3 present the variations of percent thrust parameter with fan overall pressure ratio and bypass ratio for at one inlet turbine temperature. It is observed that a higher thrust parameter it is obtained at higher bypass ratio and lower fan overall pressure ratio, so the percent thrust parameter is directly proportional with bypass ratio and inversely proportional with fan overall pressure ratio.
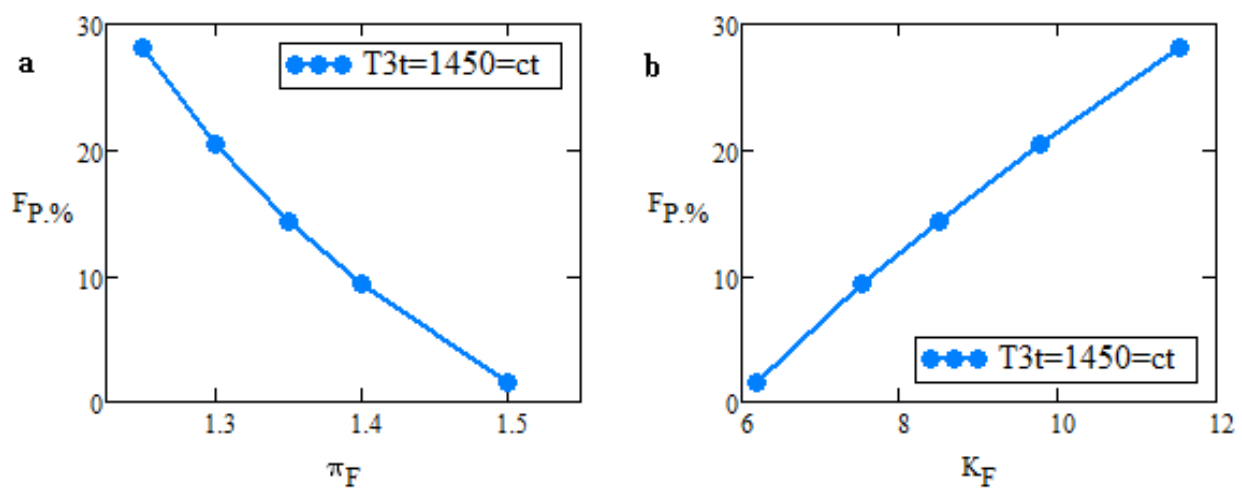

Fig. 3. Variation of thrust parameter with fan overall pressure ratio (a) and bypass ratio (b) 

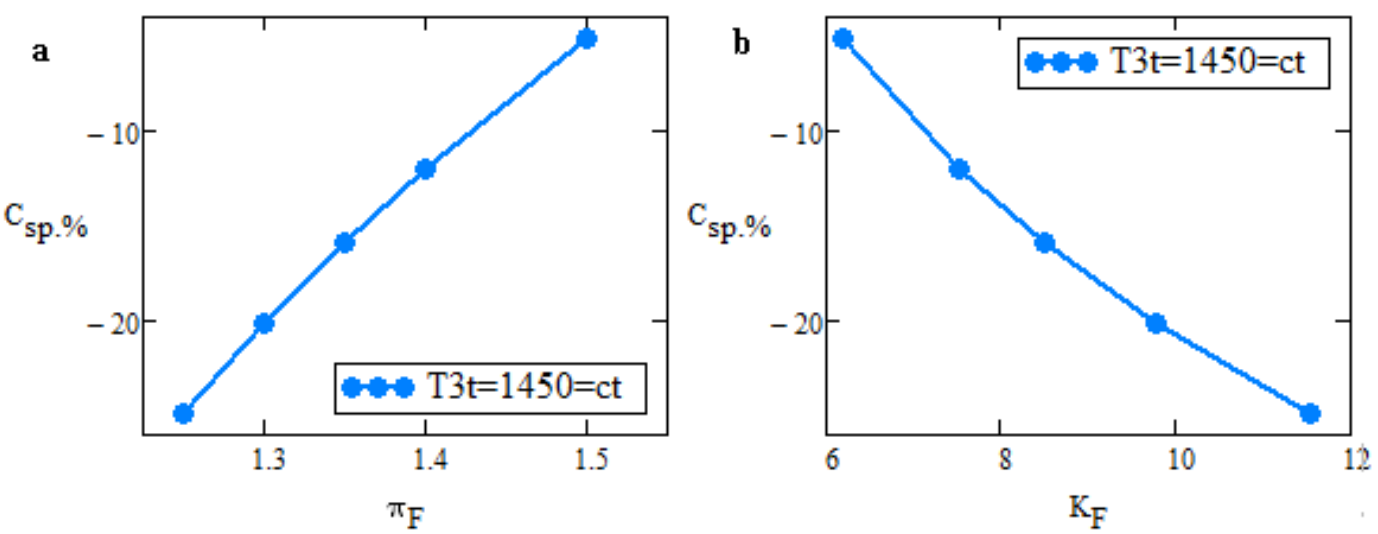

Fig. 4. Variation of specific fuel consumption parameter with fan overall pressure ratio (a) and bypass ratio (b)

The second set of diagrams from fig.4 present the variations of percent specific fuel consumption parameter with fan overall pressure ratio and bypass ratio for at one inlet turbine temperature. It is observed that a lower fuel consumption parameter it is obtained at higher bypass ratio and at lower fan overall pressure ratio, so the percent fuel consumption parameter is directly proportional with fan overall pressure ratio and inversely proportional with the bypass ratio. In conditions that is calculated the radial-axial turbofan produce different power for fan, low pressure compressor and high pressure compressor. So, the fan power is lower with 13 percent, $\mathrm{P}_{\mathrm{F} \%}=13 \%$, the LPC power is higher with 32 percent $\mathrm{P}_{\text {C.I. } \%}=33 \%$, and the HPC power is in the same value with small difference of $1 \%$ lower, $\mathrm{P}_{\text {C.II.\% }}$ $=1 \%$.
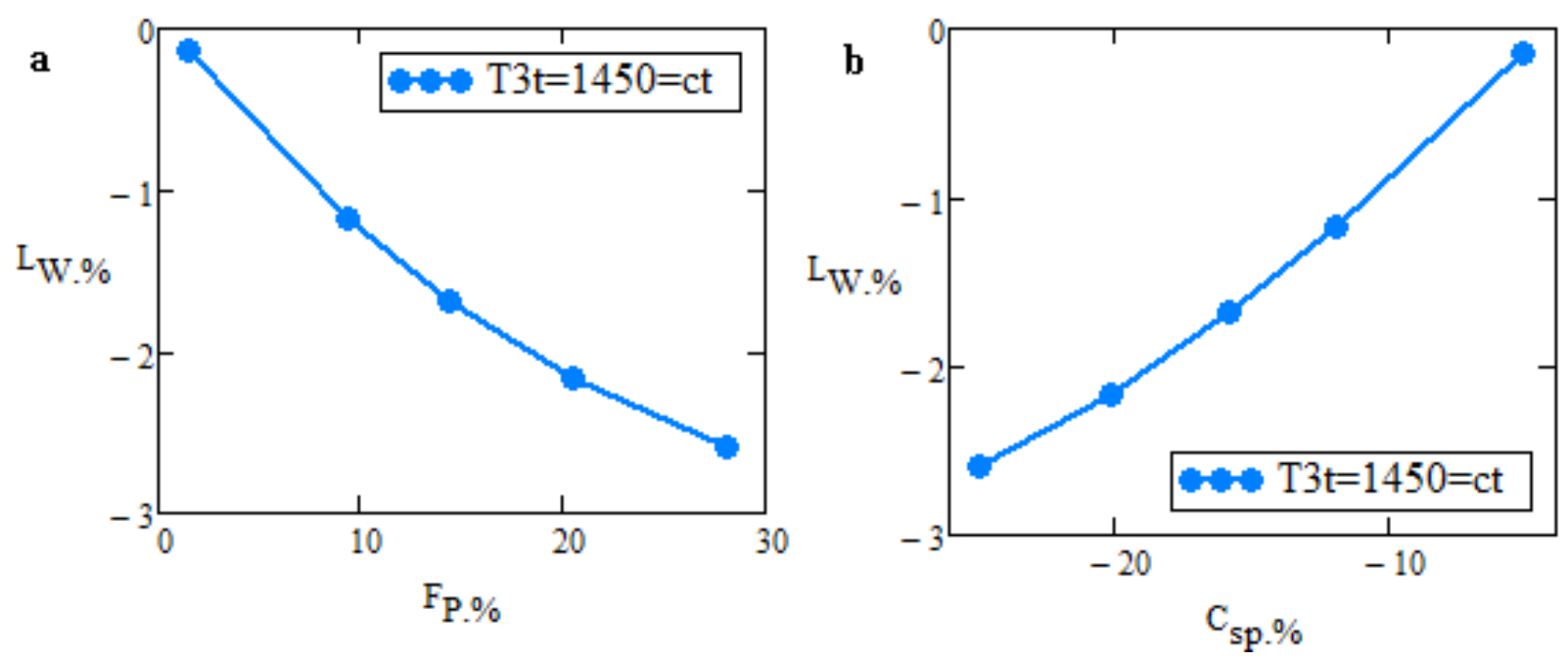

Fig. 5. Variation of noise level parameter with thrust parameter (a) and specific fuel consumption (b) parameter

The third set of diagrams from fig. 5 present the variations of percent noise level parameter with thrust parameter and specific fuel consumption parameter for at one inlet turbine temperature. It is observed that a lower noise level parameter it is obtained for a higher thrust parameter and for a lower specific fuel consumption parameter, so the noise level parameter is directly proportional with specific fuel consumption parameter and inversely proportional with the thrust parameter under the above conditions.

\section{Conclusion}

The paper presented a computing method of comparison for two types of turbofan configuration on condition of the same inlet turbine temperature, engine overall pressure ratio and power turbine and calculates the engine performance for two different turbofan engines configurations.

To establish what engine is more powerful or economic it was defined the percent thrust parameter and percent specific fuel consumption parameter. The values of these parameters evaluate de engines and decide what the improvements of radial-axial turbofan are. By the results at the same engine overall pressure ratio and inlet turbine temperature the radial-axial engine produce more thrust so is more powerful because thrust parameter is higher than one, if the fan has a low overall pressure ratio and is determined a high bypass ratio. In the same conditions the radialaxial engine is more economic because specific fuel consumption parameter is lower than one, that means the radial- 
axial turbofan has lower specific fuel consumption, if the fan has higher bypass ratio obtained by lower overall pressure ratio. Also in the same conditions the radial-axial engine is something less noisy because level noise parameter is lower than axial-engine, that means the radial-axial turbofan has lower noise level, if the fan has higher thrust parameter obtained by lower specific fuel consumption. In conclusion and in the conditions that were compared the radial-axial turbofan has a higher thrust and lower specific fuel consumption and less noisy than the axial turbofan.

\section{References}

[1] F. Haselbach, A. Newby, R. Parker, Concepts \& technologies for the next generation of large civil aircraft engines, 29th Congress of the International Council of the Aeronautical Science, St. Petersburg, Russia, September 7-12, 2014.

[2] L. Larsson, T. Grönstedt, K. Kyprianidis, CONCEPTUAL DESIGN AND MISSION ANALYSIS FOR A GEARED TURBOFAN AND AN OPEN ROTOR CONFIGURATION, Proceedings of ASME Turbo Expo, Vancouver, Canada, June 6-10, 2011.

[3] B. McKay, Next Generation Propulsion \& Air Vehicle Considerations, 45 th AIAA/ASME/SAE/ASEE joint Propulsion Conference \& Exhibit, Denver, Colorado, 2-5 August 2009.

[4] G. Wilfert, J. Sieber, A. Rolt, N.Baker, A. Touyeras, S. Colantuoni, New Environmental Friendly Aero Engine Core Concepts, ISABE, 2007.

[5] Bradley, M. K.; and Droney, C. K.: "Subsonic Ultra Green Aircraft Research: Phase I Final Report," NASA/CR2011-216847, April 2011.

[6] www.cfmaeroengines.com.

[7] R. M. Catana, G. Cican, A Global Study of the Performances of a New Turbofan Configuration, Applied Mechanics and Materials Vol. 555 (2014) pp 78-83.

[8] V. Stanciu, Fundamentals of Aviation Propulsion, Publishing house Printech, Bucharest, 2012.

[9] M. P. Boyce, Gulf Gas Turbine Engineering Handbook. Professional Publishing, Houston, 2002.

[10] R. Barron, Industrial Noise Control and Acoustics, Marcel Dekker Inc., New York, 2001. 